Published in final edited form as:

Nat Immunol. 2013 October ; 14(10): 986-995. doi:10.1038/ni.2705.

\title{
Tissue-resident macrophages
}

\author{
Luke C. Davies ${ }^{1}$, Stephen J. Jenkins ${ }^{2}$, Judith E. Allen ${ }^{3}$, and Philip R. Taylor ${ }^{1}$ \\ ${ }^{1}$ Cardiff Institute of Infection and Immunity, Cardiff University School of Medicine, Heath Park, \\ Cardiff, CF14 4XN, UK. \\ ${ }^{2}$ MRC Centre for Inflammation Research, Queens Medical Research Institute, University of \\ Edinburgh, EH16 4TJ, UK. \\ ${ }^{3}$ Centre for Immunity, Infection and Evolution, and the Institute of Immunology and Infection \\ Research, School of Biological Sciences, University of Edinburgh, Edinburgh EH9 3JT, UK.
}

\section{Abstract}

Tissue-resident macrophages are a heterogeneous population of immune cells that fulfill tissuespecific and niche-specific functions. These range from dedicated homeostatic functions, such as clearance of cellular debris and iron processing, to central roles in tissue immune-surveillance, response to infection and the resolution of inflammation. Recent studies highlight marked heterogeneity in the origins of tissue macrophages that arise from hematopoietic versus selfrenewing embryo-derived populations. We discuss the tissue-niche-specific factors that dictate cell phenotype, the definition of which will allow novel strategies to promote the restoration of tissue homeostasis. Understanding the mechanisms that dictate tissue macrophage heterogeneity should explain why simplified paradigms of macrophage activation do not explain the extent of heterogeneity seen in vivo.

\section{Introduction}

The majority of tissues in the body contain tissue-resident macrophage populations. Often several phenotypically distinct subsets are evident in discrete microanatomical niches.

Tissue-resident macrophages are extremely heterogeneous, which is a necessary consequence of tissue-specific and microanatomical niche-specific functions during development and adulthood that are integral to tissue function and homeostasis. These unique phenotypes likely reflect the heterogeneity of their origins and influence of the tissue environment in which they reside. However, these cells are best known for their role as immune sentinels in the frontline of tissue defense where they are discretely positioned and transcriptionally programmed for the encounter with pathogens or environmental challenges. The current challenges facing the field are to identify those subsets of macrophages that are specifically involved in various discrete functions, deciphering the major control mechanisms governing these functions and how these roles might be influenced by distinct macrophage origins.

Correspondence should be addressed to: P.R.T. (TaylorPR@cf.ac.uk). Cardiff Institute of Infection and Immunity, Cardiff University School of Medicine, Heath Park, Cardiff, CF14 4XN, UK. Tel: +44(0)29 20687328 ; Fax: +44(0)2920687303.

Author Contributions: All authors contributed extensively to the work presented in this paper. 


\section{Early recognition of macrophage heterogeneity}

The macrophage system was first introduced by Elie Metchnikoff in the late $19^{\text {th }}$ century ${ }^{1}$, who described its phagocytic cell activity. Macrophages were classified as part of the reticuloendothelial system ${ }^{2}$; a tissue system comprised of reticuloendothelia (phagocytes) and endothelial cells, which were proposed to have a common tissue origin. However, the early methodology used to measure phagocytosis was not restricted to macrophages and emerging morphological and functional differences between endothelial cells and macrophages led to the conclusion that the reticuloendothelial system did not accurately represent cell lineage. The awareness that macrophages can be of different origins (blood monocyte versus tissue $)^{3}$ and exhibit differing phenotypes in some settings (e.g. peroxidase activity $)^{4}$ provided evidence of heterogeneity among phagocytic cells, but not lineage divergence.

In 1968 van Furth and Cohn showed that major populations of macrophages were derived from blood monocytes ${ }^{5}$. Extension of this concept to the broader range of phagocytes including tissue macrophages established the mononuclear phagocyte system (MPS) ${ }^{6}$. MPS represented a linear model in which committed bone marrow precursors develop into blood monocytes from which tissue macrophages are derived. The model was disputed at the time due to evidence of macrophage proliferation in the tissues ${ }^{7-9}$, the perseverance of tissue macrophages ${ }^{10}$ and the presence of macrophage populations in the yolk sac before primitive hematopoiesis ${ }^{11}$. More deficiencies were detected in the absolutes of the MPS ${ }^{11,12}$, however definitive rejection of this model was limited by technologies available. Consequently, alternative hypotheses to explain macrophage heterogeneity and self-renewal in tissues failed to emerge. However by 2000 , accumulated evidence led to the conclusion that embryonic phagocytes were of a separate lineage and highlighted the possibility of their persistence into adulthood ${ }^{13}$. Recent data utilizing specific fate mapping technologies has now provided evidence for an embryonic origin of some tissue macrophages ${ }^{14-16}$.

\section{Prenatal origins for some tissue-resident macrophages}

Initial fate-mapping studies of adult macrophages were focused on microglia and Langerhans cells. Microglia are primarily derived from cells in the yolk sac ${ }^{15}$, while the origin of Langerhans cells is predominantly fetal liver with a contribution from yolk sac macrophages ${ }^{16,17}$. Langerhans cells have been historically classified as dendritic cells, however their M-CSF receptor (CSF1R) dependence during development (see below) ${ }^{18,19}$, prenatal and monocytic origins, and more recent transcriptional profiling suggest Langerhans cells can be considered as resident macrophages ${ }^{20}$. The discovery that adult Langerhans cells and microglia were established prenatally was a major break from the MPS model. These findings were extended using Myb-deficient mice that lack development of hematopoietic stem cells. Yolk sac macrophages from these mice give rise in the adult to a Myb-independent population of characteristically ' $\mathrm{F} 4 / 80^{\mathrm{hi}}$ macrophages' in several tissues, namely skin (Langerhans cell), liver (Kupffer cell), brain (microglia), pancreas, lung and spleen (red pulp macrophage) and kidney ${ }^{21}$. In normal mice, these cells co-exist with ' $\mathrm{F} 4 / 80^{\mathrm{lo}}$ macrophages', which have hematopoietic origins. Global transcriptional analysis of multiple embryonic and fetal macrophage populations indicate that these $\mathrm{F} 4 / 80^{\mathrm{hi}}$ cells, but 
not the $\mathrm{F} 4 / 80^{\mathrm{lo}}$ cells, share a common gene signature with yolk sac macrophages ${ }^{17}$. It is not yet clear, however, exactly how dominant the yolk sac macrophage versus fetal liver origins of these populations are in the tissues of the normal adult, but the clarity over their prenatal origins represents a significant paradigm shift.

In a subsequent fate mapping study, adult microglia, splenic red pulp macrophages, alveolar macrophages and $\mathrm{F} 4 / 80^{\mathrm{hi}}$ peritoneal cavity macrophages were likewise confirmed to have a prenatal origin and do not rely on blood monocytes for their renewal, at least under steadystate conditions ${ }^{22}$. A notable exception is the gastrointestinal tract, which contains large populations of resident macrophages, all of which are blood monocyte derived in the steadystate $^{23}$. However, it is evident that many tissues contain diverse populations of both local self-renewing and peripherally derived resident cells ${ }^{17,22}$, although how functionally distinct the latter populations are from monocytes is unclear. The heterogeneity of tissue macrophages is summarized in Fig. 1 and Table 1. Thus the model of the MPS needs to be extended to include not just monocytes as a major source of tissue macrophages, but to highlight the prenatal origins of many populations, some of which have been shown to involve cells arising from a distinct yolk sac-derived embryonic macrophage lineage.

\section{Maintenance of prenatal macrophages after birth}

One consequence of long-term maintenance of a prenatal population would be the requirement for self-renewal via proliferation. Human Langerhans cells are known to possess proliferative capacity ${ }^{9}$ and donor-derived Langerhans cells were still present 4.5 years after hand allograft transplantation ${ }^{24}$; similar self-renewing capacity was confirmed in mice ${ }^{25}$. One study showed Langerhans cells in adult mice are created by the local expansion of Langerhans cells in the neonate ${ }^{14}$. Brain microglia also renew themselves via local proliferation ${ }^{26}$. Additional evidence suggests both microglia and Langerhans cells can derive from blood monocytes, but only under certain conditions ${ }^{25-28}$. Similarly, we found that even in well-vascularized tissue, the classic tissue-resident peritoneal macrophages expand by proliferation in the neonate and adult ${ }^{29}$ with relative autonomy from concurrent bone marrow-derived cells ${ }^{22}$. Very recently this confirmation of proliferation has been extended to other vascularized tissues, including verification of our results in the peritoneal cavity $^{30}$.

The extent to which a self-renewing resident population is maintained throughout the life of an individual is still an open question. Experimental ablation of resident macrophages has demonstrated the capacity of bone marrow-derived cells to replace self-renewing resident cells $^{30,31}$ and this may occur under certain inflammatory regimes ${ }^{22,32}$. However, despite exhibiting markers associated with resident macrophages, it is not known if converted cells faithfully recapitulate the function of those they replace, and without reliable markers for prenatal versus monocyte-derived cells, we do not know the extent to which replacement occurs under physiological conditions. Bioinformatic analysis that compared select groups of tissue-resident macrophages has proposed tissue-specific transcriptional signatures associated with resident cells ${ }^{33}$. This type of analysis may allow a more refined assessment of resident macrophage stability, origin and function as an individual ages. Critically, the 
factors that regulate the autonomous cell survival and/or the proliferative renewal of macrophages are beginning to be identified and characterized.

\section{Growth Factors and macrophage development and maintenance}

The osteopetrotic (op/op) mouse has long been recognized as having severe defects in many macrophage populations, which were attributed to a point mutation in the gene encoding MCSF, Csf $1^{34}$. M-CSF is known to have a broad range of actions on mature myeloid cells, including regulation of macrophage differentiation, proliferation and survival ${ }^{35}$. The most obvious phenotypes of the op mutation are increased bone mass (osteopetrosis), which is attributed to loss of osteoclasts that resorb bone, and a lack of teeth, due to a failure for the tooth buds to erupt ${ }^{36}$. The macrophage deficiencies in the $o p$ mouse impact fundamentally on such tissue development processes, which highlights the importance of macrophages as a component of developing and homeostatic tissue ${ }^{36}$. Distinct macrophage subsets in various mouse tissues were found to be differentially affected by M-CSF deficiency, ranging from marked deficiencies in gut, kidney and peritoneal macrophages and peripheral monocytes to more mild impacts on liver and varied effects on splenic macrophages ${ }^{37}$. Importantly, MCSF deficiency affects macrophages with both prenatal and adult hematopoietic origins. Intriguingly, while all of the defects of the op mouse were evident in mice deficient in its receptor CSF1R, there were notable differences; principally the additional loss of Langerhans cells and microglia in Csflr-deficient mice, which were overtly normal in the $o p$ mouse. These tissue-specific 'anomalies' were explained by the alternate CSF1R ligand, interleukin 34 (IL-34). IL-34 was found to be selectively produced by keratinocytes and neurons, accounting for the defects in the prenatally derived Langerhans cells and microglia, respectively ${ }^{18,19}$. Intriguingly, IL-34 and M-CSF are expressed in different locations in the brain, suggesting the possibility of distinct outcomes of CSF1R activation by these ligands $s^{38,39}$.

Control of macrophage survival is a well-established mechanism through which MCSF regulates tissue-resident macrophage numbers ${ }^{40}$. Another critical role for M CSF is to support resident cell self-renewal. For example, the low-level proliferation exhibited by some serosal tissue-resident macrophage populations ${ }^{29,41}$ is neutralized by anti-M-CSF in adult mice ${ }^{42}$. In addition, studies using irradiation chimeras with donor cells that are deficient in either Csflr of Csf2rb have highlighted the differential requirement for M-CSF versus GM-CSF in the reconstitution by proliferation of splenic red pulp and bone marrow macrophages versus lung macrophages, respectively ${ }^{30}$. It will be critical to assess what roles these different growth factors play not only in the proliferation and/or survival of tissueresident macrophages, but also in the local definition of their tissue-specific phenotypes and functions.

\section{Tissue-resident macrophage function}

Frequently macrophages have been functionally grouped into two classes: the 'M1-M2 paradigm'. This concept has often been over-interpreted as a rigid functional classification of macrophages and not, as it was seemingly intended, a 'simplified operational concept' ${ }^{43}$. Adhering to this model, tissue-resident macrophages are classified as 'M2-like', with 
fundamental roles in tissue homeostasis that relate to the role of macrophages during development, maintenance of homeostasis and resolution of inflammation ${ }^{43,44}$. M2activation incorporates the effects of multiple mediators, such as M-CSF, TGF- $\beta$, glucocorticoids and IL-4-IL-13 (the latter specifically defined as 'alternative activation' 45) into one grouping. With respect to tissue-resident macrophages, the functional similarity with an 'M2-like' phenotype probably reflects their dependence in many settings on CSF1R and the broad availability of M-CSF in vivo, both as a macrophage survival signal and as a necessary self-renewal signal for prenatal macrophage populations. Hence the functional repertoire of tissue-resident macrophages may be intrinsically linked to their survival and/or renewal factors. However, this only remains useful if interpreted loosely as it disregards the vast diversity and specialization of function of tissue-resident macrophages in distinct microenvironments (summarized in Table 1 and discussed in more detail below). This diversity is most likely controlled in a tissue- and niche-specific manner and regulated by distinct master controls, such as discretely expressed transcription factors, which would be a useful extension to the loosely applied M1-M2 paradigm. Such factors may be induced in specific-tissue environments or may be a legacy of cellular origins and the need for selfrenewal. These niche-specific factors are largely uncharacterized, though the complexity of gene regulation in resting and activated macrophages is an area of substantial interest ${ }^{46}$. Some of the functions of tissue resident macrophages are discussed below (Fig. 2), but in many disease settings the distinction between tissue-resident and recruited inflammatory macrophages has not yet been made. In addition, it will be of considerable interest to determine if any of these tissue-resident functions are restricted to macrophages of prenatal origins or whether residence in the tissue is sufficient.

\section{Immune-surveillance and the induction of inflammation}

Tissue macrophages express a wide array of receptors for the recognition of PAMPs (pathogen-associated molecular patterns) and DAMPs (danger-associated molecular patterns): such as Toll-like receptors, NOD-like receptors, RIG-I family, lectins and scavenger receptors ${ }^{4-49}$. However, wide variation in receptor usage from tissue to tissue is evident (www.immgen.org) reflecting unique phenotypes in distinct microenvironments. This heterogeneity implicates distinct macrophage subsets in the activation of different classes of immune response to microbes and viruses. After initial recognition of microbial challenge, resident macrophages (alongside other tissue resident cells such as mast cells, dendritic cells and stromal cells) drive the influx of inflammatory leukocytes, classically neutrophils, but also monocytes as a source of inflammatory macrophages. These monocytederived macrophages rapidly dominate many inflammatory lesions becoming the majority of all macrophages present. The importance of resident macrophages in initiating inflammatory responses is illustrated by studies in which resident macrophage depletion impacts on chemokine production and neutrophil influx in experimental inflammation ${ }^{50-52}$. However, the role of resident macrophages in the initiation of the inflammatory response will vary depending on the nature of the insult ${ }^{52}$ and its magnitude ${ }^{53}$, the corresponding variety and distribution of the recognition receptors expressed, and the presence of alternate recognition systems, cellular or humoral. Depletion of resident macrophages, such as that achieved with clodronate liposomes, leads to varied consequences on challenge, which includes reduced 
host protection to infection, loss of inflammatory mediators, such as select chemokines, cytokines and lipid mediators and altered inflammatory cell recruitment ${ }^{50,52,54,55}$. Such methods however, likely deplete multiple populations of macrophages, and the specific roles of particular sub-populations need to be determined.

\section{Fate of activated resident macrophages}

The fate of resident macrophage populations and their contribution to the priming of adaptive immunity and tissue homeostasis after insult or infection has received considerable attention. After injury to serosal tissues such as the peritoneal cavity, recovery of activated resident macrophages is initially low and has been characterized as a "disappearance reaction" 90 . This disappearance can be due to increased tissue adherence, tissue emigration through draining lymphatics and possibly cell death ${ }^{56}$.

We have quantified macrophage subsets in mild zymosan peritonitis. In this model, we observe an acute neutrophilic influx, which is resolved in a day, followed by a prolonged retention of inflammatory monocyte-derived macrophages within the lesion $29,42,57$. During the period of acute neutrophil influx, fewer numbers of resident $\mathrm{F} 4 / 80^{\mathrm{hi}} \mathrm{Tim} 4^{+}$macrophages can be recovered from the inflamed tissue. However, at later time points substantial numbers of resident macrophages can be recovered, which suggests that some resident macrophages remain at the inflammatory site, presumably not recovered earlier because of increased adherence ${ }^{29}$. Increased adherence to the mesothelium has been reported during peritonitis, as well as the potential for emigration to draining lymph nodes ${ }^{58}$; however these cells were insufficiently characterized and the question of where the cells go needs to be revisited with highly purified cells and/or specific fate mapping approaches.

A similar "disappearance" of alveolar macrophages from bronchoalveolar lavage fluid occurs during influenza infection ${ }^{59}$. Mobilization of alveolar macrophages, detected via their selective Siglec-F expression, to the draining lymph nodes during bacterial infection has been reported ${ }^{60}$, suggesting a potential role in transporting antigen. Migration of alveolar macrophages from tissue to lymph node has not been definitively proven, however, as it is possible that phenotypically similar cells arise in the lymph nodes by alternative means. Others have proposed that migration does not happen ${ }^{61}$ and analysis of whole tissue indicates that resident alveolar macrophages are relatively stable in number during inflammation ${ }^{62}$. However, in situ self-renewal of alveolar macrophages during inflammation could mask any net cellular loss. These results indicate many resident macrophages remain throughout inflammation. Some tissue resident macrophages may emigrate to the draining lymphatics, but this needs specific confirmation. Thus, tissue-resident macrophages have the potential to influence the progression of the inflammatory responses and subsequent return to homeostasis.

Although an inflammatory response typically involves invasion of the tissue by monocytederived macrophages, in the context of $\mathrm{T}_{\mathrm{H}} 2$ immunity, IL- 4 can drive tissue-resident macrophage populations to expand by proliferation in the absence of peripheral monocyte recruitment ${ }^{41}$. During helminth infection IL-4, likely from $\mathrm{T}_{\mathrm{H}} 2 \mathrm{~T}$ cells, causes tissueresident macrophages to accumulate far beyond their homeostatic numbers, without the 
damaging consequences of inflammatory cell recruitment. However, the function of IL-4activated macrophages is not yet fully understood, and beyond potential roles in parasite control they may have 'resident-like' functions in maintaining homeostasis and tissue integrity in the context of chronic helminth infection ${ }^{63}$. The situation in the gastrointestinal tract provides another unique perspective, as blood monocytes are continually recruited to this tissue where they give rise to a resident population that produces IL-10 and which are resistant to Toll-like receptor signals. However, upon inflammatory insult, this in situ conversion is stopped and pro-inflammatory monocytes accumulate ${ }^{23}$.

\section{Post-inflammatory replenishment of tissue macrophages}

Recent studies in the peritoneal cavity demonstrate that even during an inflammatory response tissue-resident macrophages are maintained locally by proliferative self-renewal ${ }^{29}$. On recovery from the inflammatory episode, tissue-resident macrophages exhibit enhanced proliferation in response to M-CSF to repopulate inflamed tissues ${ }^{81}$. In contrast, evidence for replenishment of tissue-resident macrophages by recruited monocytes is lacking 29,64 . Collectively, these data demonstrate that recruited versus tissue resident macrophages can be maintained as independent populations during inflammation and its resolution (Fig. 1). The finding that peritoneal tissue-resident macrophages can persist during an inflammatory response, recovering their numbers by local proliferative self-renewal, without need for input from the periphery in a vascular tissue ${ }^{29}$, are similar to observations made in the brain $^{65}$ and lung ${ }^{30}$.

The homeostatic recovery of the resident population raises the question of the fate of the inflammatory monocyte-derived macrophages. In the peritoneal cavity and other tissues, these cells have been suggested to exit via the lymphatics or recirculate ${ }^{58,66,67}$. In experimental acute lung injury models, many inflammatory macrophages undergo Fasmediated cell death, while the resident alveolar cells persist ${ }^{62}$. These observations do not exclude the possibility that recruited bone marrow-derived cells undergo in situ phenotypic conversion to become tissue-resident macrophages, which may occur during inflammation ${ }^{22}$ or after experimental deletion of tissue-resident macrophages (e.g. after experimental whole body irradiation $)^{18,30}$. The functional equivalence of prenatally-derived tissue resident cells with their hematopoietic cell replacements needs investigation and will rely on markers for resident cell function that are more robust than the limited markers currently available such as F4/80 expression. While many of these observations have been made in experimental mouse models, evidence from human clinical settings in the context of kidney disease ${ }^{68,69}$ and acute liver failure ${ }^{70}$ indicates that macrophage proliferation does occur. However, in these settings the origins of the macrophages are not known and mouse inflammation models have shown proliferation of both bone marrow-derived inflammatory and resident macrophages during inflammation ${ }^{41,42}$

\section{Resolution of inflammation and wound healing}

During the resolution of inflammation, macrophages promote the return to homeostasis by removal of apoptotic cells and cell debris and contributing to every stage of damage repair $^{71}$. Inflammatory bone marrow-derived macrophages, are often greater in number than 
tissue-resident cells during much of the resolution phase and have been ascribed active roles in the resolution of inflammation and wound repair ${ }^{72}$. Thus the contribution of tissueresident cells has largely been neglected. Nonetheless, the importance of macrophages in wound healing is underscored by time-dependent conditional depletion of macrophages in mice $^{71}$. Depletion in the inflammatory phase demonstrated roles for macrophages in the formation of vascularized granulation tissue, epithelialization and minimizing scar formation. Depletion during the tissue formation stage led to hemorrhage and a failure of wound closure. However, macrophage depletion models do not prove a direct role for macrophages in repair but may reflect their ability to provide trophic support to, or communicate with, other cell types that are more central to repair such as fibroblasts ${ }^{73}$ or fibro/adipogenic progenitors ${ }^{74}$. A distinct role of tissue-resident macrophages in repair processes are emerging in the regulation of apoptotic cell clearance during the resolution of inflammation ${ }^{75}$. In the CNS a better distinction between the activities of resident cells (microglia) and recruited inflammatory macrophages has been made. Microglia, like other tissue-resident macrophages, have well-established roles in both immune surveillance and in clearance of cell debris, matrix and protein deposits (such as amyloid- $\beta$ ) as well as homeostatic production of growth factors, that collectively promote neuronal integrity ${ }^{76}$. However, while microglia can be deleterious to tissue function under pathological stimulation, they also stimulate recruitment of inflammatory macrophages from the periphery that promote resolution of tissue injury ${ }^{77}$.

\section{Clearance of cell debris and maintenance of homeostasis}

Macrophages play fundamental homeostatic roles in the clearance of apoptotic cells in multiple tissues and the primarily non-phlogistic response ${ }^{75,78}$. Studies, largely involving complement-deficiency, led to the development of the 'waste disposal hypothesis' of autoimmunity, in which defective clearance of autoantigens present on apoptotic cells drives the development of disease ${ }^{79}$. A key example is the tingible body macrophage in the spleen (Table 1).

Recent studies in lipoxygenase-deficient mice indicate that tissue macrophages may not leave their capture of apoptotic cells entirely to chance, having evolved strategies for limiting apoptotic cell clearance by inflammatory macrophages ${ }^{80}$. In the peritoneal cavity, modified lipids present on the surface of 12/15-lipoxygenase-expressing tissue-resident macrophages act as a sink for milk fat globule-EGF factor 8 (MFGE8), sequestering this apoptotic cell opsonin ${ }^{81}$ from the inflammatory environment. These tissue-resident macrophages also express the phosphatidylserine receptor Tim-4 (refs 82,83 ) allowing efficient phagocytosis of apoptotic cells in the absence of MFG-E8. However, inflammatory monocyte-derived macrophages are more dependent on MFG-E8 and thus exhibit impaired uptake of apoptotic cells as a consequence of the MFG-E8 sink on the tissue-resident macrophages. The consequence of this restricted 12/15-lipoxygenase expression is to effectively create a sorting system for apoptotic cells that promotes their clearance by tissueresident and not inflammatory bone marrow-derived macrophages. This process is hypothesized to help maintain tolerance by the appropriate disposal of self antigen ${ }^{80}$. However, even though inflammatory monocyte-derived macrophages are less efficient they greatly outnumber resident cells in many inflammatory contexts, and will likely still 
phagocytose a substantial number of apoptotic cells. Such fundamental processes are unlikely to be controlled by a single regulatory mechanism, especially considering the diversity of apoptotic cell recognition systems that have been described ${ }^{78}$. Macrophages and dendritic cells are proposed to differentially express the apoptotic cell receptors Mertk, Axl and Tyro3 (ref. ${ }^{84}$ ), which may further regulate these clearance processes. To exemplify, Mertk, a receptor preferentially expressed by tissue-resident macrophages ${ }^{33}$, has an increasingly well-defined role in apoptotic cell clearance and the prevention of autoimmunity ${ }^{85}$.

Erythroid cells develop into mature enucleated erythrocytes during definitive erythropoiesis, which occurs in 'blood islands' in the bone marrow and fetal liver. Macrophages within the blood islands support erythropoiesis and phagocytose the expelled nuclei, which have phosphatidyserine exposed on their surface, a clear parallel to clearance of apoptotic cells $^{86-88}$.

DNase II-deficient mice highlight the importance of the degradation of cellular debris in this erythropoietic tissue-specific context ${ }^{87}$. DNase II deficiency is embryonically lethal due to a severe anemia at the time of definitive hematopoeisis ${ }^{89}$. Anemia occurs because the macrophages of the embryo contain undigested DNA in tissues where regulated cell death occurs during development. This scenario results in abundant production of interferon- $\beta$ (IFN- $\beta$ ), which leads a feedback inhibition process that interrupts erythropoiesis. Critically, DNAase II-deficient mice can be rescued from lethality when they also lack the IFN- $\beta$ receptor Ifnar $1^{90}$.

Macrophages, primarily in the spleen (red pulp) and liver (Kupffer cells), are also central to iron homeostasis by recycling iron obtained from hemoglobin. Damaged or senescent erythrocytes that display altered surface membranes are phagocytosed and proteolytically degraded by macrophages, which release hemoglobin and ultimately iron that is stored as ferritin complexes or exported via ferroportin ${ }^{91}$. When hemoglobin is released in the circulation (for example, by damage to erythrocytes), it is bound to haptoglobin and recognized by the scavenger receptor CD163 and cleared by macrophages ${ }^{92}$. A secondary system for heme clearance exists by binding to hemopexin, which is cleared via recognition by $\mathrm{CD} 91$ expressed on macrophages ${ }^{93}$.

Some of the most critical roles of tissue-resident macrophages may prove to be in energy homeostasis. For example a severe reduction in adipose tissue-resident macrophages in Trib1-deficient mice ${ }^{94}$ contributes to insulin resistance when they are fed a high fat diet. In addition, IL-4-activation of resident adipose tissue macrophages is responsible for PPAR 8 dependent maintenance of insulin sensitivity ${ }^{95,96}$. Similarly, IL-4Ra-activated Kupffer cells regulate lipid metabolism in hepatocytes through PPAR $\delta^{97,}$, 8 . Intriguingly, IL-4 stimulated macrophages resident in adipose tissue produce catecholamines, which promote heat generation by brown adipose tissue and lipolysis of stored fat in white adipose, thus allowing adaptation to cold temperatures ${ }^{99}$. 


\section{The spleen: specialization in discrete tissue niches}

Spleen anatomy and, as a consequence, the heterogeneity of splenic macrophages has been studied in relatively high detail both under homeostasis and during infectious challenges. As a consequence it serves as a useful example to illustrate both the localization of relatively well-characterized specific functions to distinct macrophage subsets in discrete microanatomical niches ${ }^{47,100-102}$ (Fig. 3) and also to consider site-specific 'master controls' of development and/or function. Analogous developmental control systems have been described in other tissue-resident macrophage populations (Table 1) and it is likely that the principles of the discretely controlled functional heterogeneity of the spleen can be extrapolated, taking into account tissue-specific requirements, to other tissues.

In the splenic red-pulp arterial blood arrives into an 'open system', without endothelial lining and then exits via venous sinuses ${ }^{101}$. Red-pulp macrophages are an example of a macrophage subset that is seeded pre-natally ${ }^{22}$ and maintained without significant monocytic input ${ }^{30}$. In the mouse, red-pulp macrophages are identified by their $\mathrm{F} 4 / 80^{+} \mathrm{CD} 206^{+} \mathrm{CD} 11 \mathrm{~b}^{\mathrm{lo} /-}$ phenotype and selectively express the transcription factor Spi-C. A major function of red pulp macrophages is to phagocytose aged erythrocytes as they pass through the red pulp ${ }^{101}, 103$. Their importance in iron processing is evident from the study of Spi-C-deficient mice ${ }^{103}$. These mutant mice exhibit a very specific absence of splenic red pulp macrophages, and thus impaired clearance of erythrocytes and a build up of iron in the red pulp.

The splenic marginal zone is a region rich in B cells and several specialized types of macrophages. In the 'outer layer' of the marginal zone, marginal zone macrophages express abundant select scavenger and pattern recognition receptors ${ }^{104-107}$, such as CD204 (Scavenger receptor A), MARCO (Macrophage receptor with collagenous structure) and CD209b (SIGN-R1, a DC-SIGN homologue), and are well placed microanatomically to capture blood-borne antigens ${ }^{47}, 101,102,104$. Marginal zone macrophages have been shown to regulate the retention of marginal zone B cells, a process in which MARCO is implicated ${ }^{108}$. B cells in turn are needed to establish the architecture of the splenic marginal zone ${ }^{101,102}$. The development of both marginal zone and metallophilic macrophages is regulated by the nuclear receptor LXR1a $(N r 1 h 3)^{109}$.

The 'metallophilic' or 'marginal zone metallophilic' macrophages, present in the 'inner layer' of the marginal zone are identified by discrete expression of select markers, such as CD169 (Sialoadhesin or Siglec-1 - Sialic acid binding Ig-like lectin-1). The initial observation that metallophilic macrophages produce type-I IFN after viral infection suggested a role in antiviral responses ${ }^{110}$, but roles in bacterial infection have also been proposed $^{111}$. One study of vesicular stomatitis virus showed that the type-1 IFN response is suppressed in metallophilic macrophages allowing them to become a reservoir of replicating virus that drives an effective adaptive immune response ${ }^{112}$. Targeting of antigen to metallophilic macrophages appears to facilitate the generation of cytotoxic $\mathrm{T}$ cells after transfer of blood-borne antigen or adenovirus to $\mathrm{CD} 8^{+}$dendritic cells ${ }^{113}$. Collectively, these studies indicate that the marginal zone and metallophilic macrophages act in immune- 
surveillance and are excellently positioned to capture blood-borne pathogens and regulate the subsequent adaptive immune responses.

In the splenic white pulp, macrophages can be identified by their expression of the panmacrophage marker CD68. Among these, tingible body macrophages present in the germinal centers were named because of their histochemical staining pattern. Their 'unique' staining results from apoptotic cell debris and associated chromatin, which is derived from the phagocytic clearance of dead, activated lymphocytes that result from the germinal center reaction ${ }^{100}$. MFG-E8 and the receptor tyrosine kinase Mertk ${ }^{114}$ are important for the clearance of apoptotic cells by tingible body macrophages. In this setting, germinal center defects in apoptotic cell clearance have been suggested to cause alterations in B cell tolerance and lead to the production of autoantibodies ${ }^{81,114}$.

\section{Conclusions}

Transcriptional profiling of macrophages from different tissue locations, from the embryo to the adult has identified, and will continue to identify, core features of tissue resident macrophages ${ }^{17,33}$. Clear validation of this approach can be seen by the identification of Spi$\mathrm{C}$ transcriptional networks in splenic red pulp macrophages after the discovery that Spi-C plays a critical role in red pulp macrophage development ${ }^{103}$. It is reasonable to assume that there will be many discrete transcriptional controls for individual tissue resident macrophage populations. Transcription factors and epigenetic regulators will be identified that are not just important for the development of tissue resident macrophage populations, but that regulate key functional characteristics of those cells and without which their characteristic phenotype would be markedly altered. This will begin to explain the extreme diversity and heterogeneity seen both between and within distinct tissue resident macrophage populations.

Furthermore, understanding the distinct developmental origins of many tissue resident macrophage populations, including their need for renewal during homeostasis and disease, will provide insights into fundamental differences between inflammatory monocyte-derived macrophages and their tissue resident 'cousins'. At this time it is not known whether the distinct origins of tissue macrophages (for example yolk sac versus hematopoietic) has any impact on the function of the resultant tissue macrophages. At the very least, one may expect that the requirement for the mature prenatal derived cells to exist in a seemingly quiescent state and yet remain competent to proliferate as a mature cell (during homeostasis or inflammation) must be under defined transcriptional control. This control, which itself will be refined by local environment-specific factors, will undoubtedly impact on the function and phenotype of the cell. Defining key transcriptional control elements should provide opportunities to manipulate one branch of the 'family' preferentially, for example to modulate the activity of inflammatory monocyte-derived macrophages whilst limiting impact on homeostatic tissue resident macrophage functions, and vice versa. A herculean effort will be needed to extrapolate the novel findings from global transcriptomic and elegant fate mapping studies to discrete clinically relevant settings, in specific tissues. Ultimately this will identify novel mechanisms through which tissue-resident macrophages may be manipulated for therapeutic benefit, not simply in the context of immune disease, but in regulation of tissue physiology in general. 


\section{References}

1. Metchnikoff E. Leçons sur la pathologie comparée de l'inflammation. Paris, Masson. 1892

2. Aschoff L. Das reticuloendotheliale System. Erg. Inn. Med. Kinderheilk. 1924; 26

3. Sabin FR, Doan CA, Cunningham RS. Discrimination of two types of phagocytic cells in the connective tissues by the supravital technique. Contrib. Embryol. (Am). 1925; 16:125-162.

4. Daems WT, Brederoo P. The Fine Structure and Peroxidase Activity of Resident and Exudate Peritoneal Macrophages in the Guinea Pig. The Reticuloendothelial System and Immune Phenomena: Advances in Experimental Medicine and Biology. 1971; 15:19-31.

5. van Furth R, Cohn ZA. The origin and kinetics of mononuclear phagocytes. J Exp Med. 1968; 128:415-435. [PubMed: 5666958]

6. van Furth R, et al. The mononuclear phagocyte system: a new classification of macrophages, monocytes, and their precursor cells. Bull World Health Organ. 1972; 46:845-852. [PubMed: 4538544]

7. Parwaresch MR, Wacker HH. Origin and kinetics of resident tissue macrophages. Parabiosis studies with radiolabelled leucocytes. Cell Tissue Kinet. 1984; 17:25-39. [PubMed: 6692464]

8. Sawyer RT, Strausbauch PH, Volkman A. Resident macrophage proliferation in mice depleted of blood monocytes by strontium-89. Lab Invest. 1982; 46:165-170. [PubMed: 6174824]

9. Czernielewski JM, Demarchez M. Further evidence for the self-reproducing capacity of Langerhans cells in human skin. J Invest Dermatol. 1987; 88:17-20. [PubMed: 3540136]

10. Melnicoff MJ, Horan PK, Breslin EW, Morahan PS. Maintenance of peritoneal macrophages in the steady state. J Leukoc Biol. 1988; 44:367-375. [PubMed: 2460572]

11. Naito M, et al. Development, differentiation, and phenotypic heterogeneity of murine tissue macrophages. J Leukoc Biol. 1996; 59:133-138. [PubMed: 8603984]

12. Takahashi K. Development and Differentiation of Macrophages and Related Cells: Historical Review and Current Concepts. J Clin Exp Hematopathol. 2000; 41:1-31.

13. Lichanska AM, Hume DA. Origins and functions of phagocytes in the embryo. Exp Hematol. 2000; 28:601-611. [PubMed: 10880746]

14. Chorro L, et al. Langerhans cell (LC) proliferation mediates neonatal development, homeostasis, and inflammation-associated expansion of the epidermal LC network. J Exp Med. 2009; 206:3089-3100. [PubMed: 19995948]

15. Ginhoux F, et al. Fate mapping analysis reveals that adult microglia derive from primitive macrophages. Science. 2010; 330:841-845. [PubMed: 20966214] [These studies demonstrate the early-embryonic origins of adult microglia, which are maintained throughout life by local selfrenewal (see reference 13).]

16. Hoeffel G, et al. Adult Langerhans cells derive predominantly from embryonic fetal liver monocytes with a minor contribution of yolk sac-derived macrophages. J Exp Med. 2012; 209:1167-1181. [PubMed: 22565823]

17. Schulz C, et al. A Lineage of Myeloid Cells Independent of Myb and Hematopoietic Stem Cells. Science. 2012; 336:86-90. [PubMed: 22442384] [Demonstration of the clear potential for widespread tissue seeding of macrophages from the yolk sac.]

18. Greter M, et al. Stroma-derived interleukin-34 controls the development and maintenance of langerhans cells and the maintenance of microglia. Immunity. 2012; 37:1050-1060. [PubMed: 23177320]

19. Wang Y, et al. IL-34 is a tissue-restricted ligand of CSF1R required for the development of Langerhans cells and microglia. Nat Immunol. 2012; 13:753-760. [PubMed: 22729249]

[Important tissue specific role for IL-34 in the development/maintenance of Langerhans cells and microglia (see also 18 above).]

20. Satpathy AT, Wu X, Albring JC, Murphy KM. Re(de)fining the dendritic cell lineage. Nat Immunol. 2012; 13:1145-1154. [PubMed: 23160217]

21. Schulz C, et al. A Lineage of Myeloid Cells Independent of Myb and Hematopoietic Stem Cells. Science. 2012; 336:86-90. [PubMed: 22442384] 
22. Yona S, et al. Fate Mapping Reveals Origins and Dynamics of Monocytes and Tissue Macrophages under Homeostasis. Immunity. 2012; 38:79-91. [PubMed: 23273845]

23. Bain CC, et al. Resident and pro-inflammatory macrophages in the colon represent alternative context-dependent fates of the same Ly6C(hi) monocyte precursors. Mucosal Immunol. 2012; 6:498-510. [PubMed: 22990622]

24. Kanitakis J, Petruzzo P, Dubernard JM. Turnover of epidermal Langerhans' cells. N Engl J Med. 2004; 351:2661-2662. [PubMed: 15602033]

25. Merad M, et al. Langerhans cells renew in the skin throughout life under steady-state conditions. Nat Immunol. 2002; 3:1135-1141. [PubMed: 12415265]

26. Ajami B, Bennett JL, Krieger C, Tetzlaff W, Rossi FM. Local self-renewal can sustain CNS microglia maintenance and function throughout adult life. Nat Neurosci. 2007; 10:1538-1543. [PubMed: 18026097] [Demonstration of the autonomy of adult microglia from potential peripheral progenitors.]

27. Mildner A, et al. Microglia in the adult brain arise from Ly-6ChiCCR2+ monocytes only under defined host conditions. Nat Neurosci. 2007; 10:1544-1553. [PubMed: 18026096]

28. Capotondo A, et al. Brain conditioning is instrumental for successful microglia reconstitution following hematopoietic stem cell transplantation. Proc Natl Acad Sci U S A. 2012; 109:1501815023. [PubMed: 22923692]

29. Davies LC, et al. A quantifiable proliferative burst of tissue macrophages restores homeostatic macrophage populations after acute inflammation. Eur J Immunol. 2011; 41:2155-2164.

[PubMed: 21710478] [First demonstration that tissue resident macrophages in vascular tissues can renew by local proliferation without significant monocytic input.]

30. Hashimoto D, et al. Tissue-Resident Macrophages Self-Maintain Locally throughout Adult Life with Minimal Contribution from Circulating Monocytes. Immunity. 2013; 38:792-804. [PubMed: 23601688] [Demonstration of the clear potential for widespread tissue seeding of macrophages from the yolk sac.]

31. Landsman L, Varol C, Jung S. Distinct differentiation potential of blood monocyte subsets in the lung. J Immunol. 2007; 178:2000-2007. [PubMed: 17277103]

32. Hettinger $\mathbf{J}$, et al. Origin of monocytes and macrophages in a committed progenitor. Nat Immunol. 2013; 14:821-830. [PubMed: 23812096]

33. Gautier EL, et al. Gene-expression profiles and transcriptional regulatory pathways that underlie the identity and diversity of mouse tissue macrophages. Nat Immunol. 2012; 13:1118-1128. [PubMed: 23023392]

34. Yoshida $\mathrm{H}$, et al. The murine mutation osteopetrosis is in the coding region of the macrophage colony stimulating factor gene. Nature. 1990; 345:442-444. [PubMed: 2188141]

35. Hamilton JA. Colony-stimulating factors in inflammation and autoimmunity. Nat Rev Immunol. 2008; 8:533-544. [PubMed: 18551128]

36. Pollard JW. Trophic macrophages in development and disease. Nat Rev Immunol. 2009; 9:259_ 270. [PubMed: 19282852]

37. Ryan GR, et al. Rescue of the colony-stimulating factor 1 (CSF-1)-nullizygous mouse (Csf1(op)/ Csf1(op)) phenotype with a CSF-1 transgene and identification of sites of local CSF-1 synthesis. Blood. 2001; 98:74-84. [PubMed: 11418465]

38. Liu H, et al. The mechanism of shared but distinct CSF-1R signaling by the nonhomologous cytokines IL-34 and CSF-1. Biochim Biophys Acta. 2012; 1824:938-945. [PubMed: 22579672]

39. Chihara T, et al. IL-34 and M-CSF share the receptor Fms but are not identical in biological activity and signal activation. Cell Death Differ. 2010; 17:1917-1927. [PubMed: 20489731]

40. Hume DA, MacDonald KP. Therapeutic applications of macrophage colony-stimulating factor-1 (CSF-1) and antagonists of CSF-1 receptor (CSF-1R) signaling. Blood. 2012; 119:1810-1820. [PubMed: 22186992]

41. Jenkins SJ, et al. Local macrophage proliferation, rather than recruitment from the blood, is a signature of TH2 inflammation. Science. 2011; 332:1284-1288. [PubMed: 21566158] [Demonstration that parasite infection expands tissues resident macrophages in an IL-4-dependent manner without the need for monocyte recruitment.] 
42. Davies LC, et al. Distinct bone marrow-derived and tissue resident macrophage-lineages proliferate at key stages during inflammation. Nat Commun. 2013; 4:1886. doi:1810.1038/ ncomms2877. [PubMed: 23695680] [Definitive demonstration that peripherally derived inflammatory macrophages proliferate during inflammation.]

43. Mantovani A, Sica A, Locati M. Macrophage polarization comes of age. Immunity. 2005; 23:344346. [PubMed: 16226499]

44. Mantovani A, Biswas SK, Galdiero MR, Sica A, Locati M. Macrophage plasticity and polarization in tissue repair and remodelling. J Pathol. 2013; 229:176-185. [PubMed: 23096265]

45. Gordon S, Martinez FO. Alternative activation of macrophages: mechanism and functions. Immunity. 2010; 32:593-604. [PubMed: 20510870]

46. Ostuni R, et al. Latent enhancers activated by stimulation in differentiated cells. Cell. 2013; 152:157-171. [PubMed: 23332752]

47. Taylor PR, et al. Macrophage receptors and immune recognition. Annu Rev Immunol. 2005; 23:901-944. [PubMed: 15771589]

48. Akira S, Takeda K, Kaisho T. Toll-like receptors: critical proteins linking innate and acquired immunity. Nat Immunol. 2001; 2:675-680. [PubMed: 11477402]

49. Inohara N, Nunez G. NODs: intracellular proteins involved in inflammation and apoptosis. Nat Rev Immunol. 2003; 3:371-382. [PubMed: 12766759]

50. Cailhier JF, et al. Conditional macrophage ablation demonstrates that resident macrophages initiate acute peritoneal inflammation. J Immunol. 2005; 174:2336-2342. [PubMed: 15699170]

51. Maus UA, et al. Role of resident alveolar macrophages in leukocyte traffic into the alveolar air space of intact mice. Am J Physiol Lung Cell Mol Physiol. 2002; 282:L1245-1252. [PubMed: 12003780]

52. Ajuebor MN, et al. Role of resident peritoneal macrophages and mast cells in chemokine production and neutrophil migration in acute inflammation: evidence for an inhibitory loop involving endogenous IL-10. J Immunol. 1999; 162:1685-1691. [PubMed: 9973430]

53. Rosas M, et al. The induction of inflammation by dectin-1 in vivo is dependent on myeloid cell programming and the progression of phagocytosis. J Immunol. 2008; 181:3549-3557. [PubMed: 18714028]

54. Kolaczkowska E, et al. Resident peritoneal macrophages and mast cells are important cellular sites of COX-1 and COX-2 activity during acute peritoneal inflammation. Archivum Immunologiae et Therapia Experimentalis. 2009; 57:459-466.

55. Kolaczkowska E, et al. Resident peritoneal leukocytes are important sources of MMP-9 during zymosan peritonitis: superior contribution of macrophages over mast cells. Immunol Lett. 2007; 113:99-106. [PubMed: 17826846]

56. Barth MW, Hendrzak JA, Melnicoff MJ, Morahan PS. Review of the macrophage disappearance reaction. J Leukoc Biol. 1995; 57:361-367. [PubMed: 7884305]

57. Rosas M, Thomas B, Stacey M, Gordon S, Taylor PR. The myeloid 7/4-antigen defines recently generated inflammatory macrophages and is synonymous with Ly-6B. J Leukoc Biol. 2010; 88:169-180. [PubMed: 20400676]

58. Bellingan GJ, et al. Adhesion molecule-dependent mechanisms regulate the rate of macrophage clearance during the resolution of peritoneal inflammation. J Exp Med. 2002; 196:1515-1521. [PubMed: 12461086]

59. Lauder SN, et al. Paracetamol reduces influenza-induced immunopathology in a mouse model of infection without compromising virus clearance or the generation of protective immunity. Thorax. 2011; 66:368-374. [PubMed: 21310755]

60. Kirby AC, Coles MC, Kaye PM. Alveolar macrophages transport pathogens to lung draining lymph nodes. J Immunol. 2009; 183:1983-1989. [PubMed: 19620319]

61. Jakubzick C, Tacke F, Llodra J, van Rooijen N, Randolph GJ. Modulation of dendritic cell trafficking to and from the airways. J Immunol. 2006; 176:3578-3584. [PubMed: 16517726]

62. Janssen WJ, et al. Fas determines differential fates of resident and recruited macrophages during resolution of acute lung injury. Am J Respir Crit Care Med. 2011; 184:547-560. [PubMed: 21471090] 
63. Allen JE, Wynn TA. Evolution of Th2 immunity: a rapid repair response to tissue destructive pathogens. PLoS Pathog. 2011; 7:e1002003. [PubMed: 21589896]

64. Liddiard K, Rosas M, Davies LC, Jones SA, Taylor PR. Macrophage heterogeneity and acute inflammation. Eur J Immunol. 2011; 41:2503-2508. [PubMed: 21952806]

65. Ajami B, Bennett JL, Krieger C, McNagny KM, Rossi FM. Infiltrating monocytes trigger EAE progression, but do not contribute to the resident microglia pool. Nat Neurosci. 2011; 14:11421149. [PubMed: 21804537]

66. Leuschner F, et al. Rapid monocyte kinetics in acute myocardial infarction are sustained by extramedullary monocytopoiesis. J Exp Med. 2012; 209:123-137. [PubMed: 22213805]

67. Cao C, Lawrence DA, Strickland DK, Zhang L. A specific role of integrin Mac-1 in accelerated macrophage efflux to the lymphatics. Blood. 2005; 106:3234-3241. [PubMed: 16002427]

68. Isbel NM, Nikolic-Paterson DJ, Hill PA, Dowling J, Atkins RC. Local macrophage proliferation correlates with increased renal M-CSF expression in human glomerulonephritis. Nephrol Dial Transplant. 2001; 16:1638-1647. [PubMed: 11477167]

69. Yang N, et al. Local macrophage proliferation in human glomerulonephritis. Kidney Int. 1998; 54:143-151. [PubMed: 9648072]

70. Antoniades CG, et al. Source and characterization of hepatic macrophages in acetaminopheninduced acute liver failure in humans. Hepatology. 2012; 56:735-746. [PubMed: 22334567]

71. Lucas T, et al. Differential roles of macrophages in diverse phases of skin repair. J Immunol. 2010; 184:3964-3977. [PubMed: 20176743]

72. Gautier EL, et al. Systemic analysis of PPARgamma in mouse macrophage populations reveals marked diversity in expression with critical roles in resolution of inflammation and airway immunity. J Immunol. 2012; 189:2614-2624. [PubMed: 22855714]

73. Duffield JS, Lupher M, Thannickal VJ, Wynn TA. Host responses in tissue repair and fibrosis. Annu Rev Pathol. 2013; 8:241-276. [PubMed: 23092186]

74. Heredia JE, et al. Type 2 innate signals stimulate fibro/adipogenic progenitors to facilitate muscle regeneration. Cell. 2013; 153:376-388. [PubMed: 23582327]

75. Henson PM, Hume DA. Apoptotic cell removal in development and tissue homeostasis. Trends Immunol. 2006; 27:244-250. [PubMed: 16584921]

76. London A, Cohen M, Schwartz M. Microglia and monocyte-derived macrophages: functionally distinct populations that act in concert in CNS plasticity and repair. Front Cell Neurosci. 2013; 7:34. [PubMed: 23596391]

77. Shechter R, et al. Recruitment of Beneficial M2 Macrophages to Injured Spinal Cord Is Orchestrated by Remote Brain Choroid Plexus. Immunity. 2013; 38:555-569. [PubMed: 23477737]

78. Erwig LP, Henson PM. Clearance of apoptotic cells by phagocytes. Cell Death Differ. 2008; 15:243-250. [PubMed: 17571081]

79. Manderson AP, Botto M, Walport MJ. The role of complement in the development of systemic lupus erythematosus. Annu Rev Immunol. 2004; 22:431-456. [PubMed: 15032584]

80. Uderhardt S, et al. 12/15-lipoxygenase orchestrates the clearance of apoptotic cells and maintains immunologic tolerance. Immunity. 2012; 36:834-846. [PubMed: 22503541] [Demonstration that tissue resident macrophages can actively divert apoptotic cell clearance to themselves rather than recruited inflammatory monocyte-derived cells.]

81. Hanayama R, et al. Autoimmune disease and impaired uptake of apoptotic cells in MFG-E8deficient mice. Science. 2004; 304:1147-1150. [PubMed: 15155946]

82. Kobayashi N, et al. TIM-1 and TIM-4 glycoproteins bind phosphatidylserine and mediate uptake of apoptotic cells. Immunity. 2007; 27:927-940. [PubMed: 18082433]

83. Miyanishi M, et al. Identification of Tim4 as a phosphatidylserine receptor. Nature. 2007; 450:435-439. [PubMed: 17960135]

84. Seitz HM, Camenisch TD, Lemke G, Earp HS, Matsushima GK. Macrophages and dendritic cells use different Axl/Mertk/Tyro3 receptors in clearance of apoptotic cells. J Immunol. 2007; 178:5635-5642. [PubMed: 17442946] 
85. Scott RS, et al. Phagocytosis and clearance of apoptotic cells is mediated by MER. Nature. 2001; 411:207-211. [PubMed: 11346799]

86. Yoshida H, et al. Phosphatidylserine-dependent engulfment by macrophages of nuclei from erythroid precursor cells. Nature. 2005; 437:754-758. [PubMed: 16193055]

87. Nagata S. Autoimmune diseases caused by defects in clearing dead cells and nuclei expelled from erythroid precursors. Immunol Rev. 2007; 220:237-250. [PubMed: 17979851]

88. Chow A, et al. CD169(+) macrophages provide a niche promoting erythropoiesis under homeostasis and stress. Nat Med. 2013; 19:429-436. [PubMed: 23502962]

89. Kawane K, et al. Requirement of DNase II for definitive erythropoiesis in the mouse fetal liver. Science. 2001; 292:1546-1549. [PubMed: 11375492]

90. Yoshida H, Okabe Y, Kawane K, Fukuyama H, Nagata S. Lethal anemia caused by interferon-beta produced in mouse embryos carrying undigested DNA. Nat Immunol. 2005; 6:49-56. [PubMed: 15568025]

91. Ganz T. Macrophages and systemic iron homeostasis. J Innate Immun. 2012; 4:446-453. [PubMed: 22441209]

92. Kristiansen M, et al. Identification of the haemoglobin scavenger receptor. Nature. 2001; 409:198201. [PubMed: 11196644]

93. Hvidberg V, et al. Identification of the receptor scavenging hemopexin-heme complexes. Blood. 2005; 106:2572-2579. [PubMed: 15947085]

94. Satoh T, et al. Critical role of Trib1 in differentiation of tissue-resident M2-like macrophages. Nature. 2013; 495:524-528. [PubMed: 23515163]

95 . Wu D, et al. Eosinophils sustain adipose alternatively activated macrophages associated with glucose homeostasis. Science. 2011; 332:243-247. [PubMed: 21436399]

96. Odegaard JI, et al. Macrophage-specific PPARgamma controls alternative activation and improves insulin resistance. Nature. 2007; 447:1116-1120. [PubMed: 17515919]

97. Kang K, et al. Adipocyte-derived Th2 cytokines and myeloid PPARdelta regulate macrophage polarization and insulin sensitivity. Cell Metab. 2008; 7:485-495. [PubMed: 18522830]

98. Odegaard JI, et al. Alternative M2 activation of Kupffer cells by PPARdelta ameliorates obesityinduced insulin resistance. Cell Metab. 2008; 7:496-507. [PubMed: 18522831]

99. Nguyen KD, et al. Alternatively activated macrophages produce catecholamines to sustain adaptive thermogenesis. Nature. 2011; 480:104-108. [PubMed: 22101429] [Interesting demonstration of the importance of alternatively-activated macrophages in the physiological response to cold.]

100. MacLennan IC. Germinal centers. Annu Rev Immunol. 1994; 12:117-139. [PubMed: 8011279]

101. Mebius RE, Kraal G. Structure and function of the spleen. Nat Rev Immunol. 2005; 5:606-616. [PubMed: 16056254]

102. den Haan JM, Kraal G. Innate immune functions of macrophage subpopulations in the spleen. $\mathbf{J}$ Innate Immun. 2012; 4:437-445. [PubMed: 22327291]

103. Kohyama M, et al. Role for Spi-C in the development of red pulp macrophages and splenic iron homeostasis. Nature. 2009; 457:318-321. [PubMed: 19037245] [Demonstration of the restriction of Spi-C expression to red pulp macrophages and its selective importance for their red pulp macrophage development and hence for splenic iron homeostasis.]

104. Geijtenbeek TB, et al. Marginal zone macrophages express a murine homologue of DC-SIGN that captures blood-borne antigens in vivo. Blood. 2002; 100:2908-2916. [PubMed: 12351402]

105. Elomaa O, et al. Cloning of a novel bacteria-binding receptor structurally related to scavenger receptors and expressed in a subset of macrophages. Cell. 1995; 80:603-609. [PubMed: 7867067]

106. Kang YS, et al. The C-type lectin SIGN-R1 mediates uptake of the capsular polysaccharide of Streptococcus pneumoniae in the marginal zone of mouse spleen. Proc Natl Acad Sci U S A. 2004; 101:215-220. [PubMed: 14694198]

107. Lanoue A, et al. SIGN-R1 contributes to protection against lethal pneumococcal infection in mice. J Exp Med. 2004; 200:1383-1393. [PubMed: 15583012]

108. Karlsson MC, et al. Macrophages control the retention and trafficking of B lymphocytes in the splenic marginal zone. J Exp Med. 2003; 198:333-340. [PubMed: 12874264] 
109. A-Gonzalez N, et al. The Nuclear Receptor LXRa controls the functional specialization of splenic macrophages. Nat Immunol. 2013; 14:831-839. [PubMed: 23770640]

110. Eloranta ML, Alm GV. Splenic marginal metallophilic macrophages and marginal zone macrophages are the major interferon-alpha/beta producers in mice upon intravenous challenge with herpes simplex virus. Scand J Immunol. 1999; 49:391-394. [PubMed: 10219764]

111. Klaas M, et al. Sialoadhesin promotes rapid proinflammatory and type I IFN responses to a sialylated pathogen, Campylobacter jejuni. J Immunol. 2012; 189:2414-2422. [PubMed: 22851711]

112. Honke N, et al. Enforced viral replication activates adaptive immunity and is essential for the control of a cytopathic virus. Nat Immunol. 2011; 13:51-57. [PubMed: 22101728] [Interesting selective role for splenic metallophilic macrophages as a potential infectious viral reservoir that drives adaptive immunity.]

113. Backer R, et al. Effective collaboration between marginal metallophilic macrophages and CD8+ dendritic cells in the generation of cytotoxic T cells. Proc Natl Acad Sci U S A. 2010; 107:216221. [PubMed: 20018690]

114. Khan TN, Wong EB, Soni C, Rahman ZS. Prolonged Apoptotic Cell Accumulation in Germinal Centers of Mer-Deficient Mice Causes Elevated B Cell and CD4+ Th Cell Responses Leading to Autoantibody Production. J Immunol. 2013; 190:1433-1446. [PubMed: 23319738]

115. Carlin LM, et al. Nr4a1-Dependent Ly6C(low) Monocytes Monitor Endothelial Cells and Orchestrate Their Disposal. Cell. 2013; 153:362-375. [PubMed: 23582326]

116. Chow A, et al. Bone marrow CD169+ macrophages promote the retention of hematopoietic stem and progenitor cells in the mesenchymal stem cell niche. J Exp Med. 2011; 208:261-271.

[PubMed: 21282381]

117. Quinn JM, et al. Calcitonin receptor antibodies in the identification of osteoclasts. Bone. 1999; 25:1-8. [PubMed: 10423015]

118. Sadahira Y, Mori M. Role of the macrophage in erythropoiesis. Pathol Int. 1999; 49:841-848. [PubMed: 10571815]

119. Paolicelli RC, et al. Synaptic pruning by microglia is necessary for normal brain development. Science. 2011; 333:1456-1458. [PubMed: 21778362]

120. Prinz M, Priller J, Sisodia SS, Ransohoff RM. Heterogeneity of CNS myeloid cells and their roles in neurodegeneration. Nat Neurosci. 2011; 14:1227-1235. [PubMed: 21952260]

121. Zigmond E, Jung S. Intestinal macrophages: well educated exceptions from the rule. Trends Immunol. 2013; 34:162-168. [PubMed: 23477922]

122. Klein I, et al. Kupffer cell heterogeneity: functional properties of bone marrow derived and sessile hepatic macrophages. Blood. 2007; 110:4077-4085. [PubMed: 17690256]

123. Hashimoto D, Miller J, Merad M. Dendritic cell and macrophage heterogeneity in vivo. Immunity. 2011; 35:323-335. [PubMed: 21943488]

124. Carey B, Trapnell BC. The molecular basis of pulmonary alveolar proteinosis. Clin Immunol. 2010; 135:223-235. [PubMed: 20338813]

125. Murphy J, Summer R, Wilson AA, Kotton DN, Fine A. The prolonged lifespan of alveolar macrophages. Am J Respir Cell Mol Biol. 2008; 38:380-385. [PubMed: 18192503]

126. Bedoret $\mathrm{D}$, et al. Lung interstitial macrophages alter dendritic cell functions to prevent airway allergy in mice. J Clin Invest. 2009; 119:3723-3738. [PubMed: 19907079]

127. Taylor PR, et al. The beta-glucan receptor, dectin-1, is predominantly expressed on the surface of cells of the monocyte/macrophage and neutrophil lineages. J Immunol. 2002; 169:3876-3882. [PubMed: 12244185]

128. Dioszeghy V, et al. 12/15-Lipoxygenase regulates the inflammatory response to bacterial products in vivo. J Immunol. 2008; 181:6514-6524. [PubMed: 18941242]

129. Cailhier JF, et al. Resident pleural macrophages are key orchestrators of neutrophil recruitment in pleural inflammation. Am J Respir Crit Care Med. 2006; 173:540-547. [PubMed: 16357332]

130. Chorro L, Geissmann F. Development and homeostasis of 'resident' myeloid cells: the case of the Langerhans cell. Trends Immunol. 2010; 31:438-445. [PubMed: 21030305] 
131. Merad M, Ginhoux F, Collin M. Origin, homeostasis and function of Langerhans cells and other langerin-expressing dendritic cells. Nat Rev Immunol. 2008; 8:935-947. [PubMed: 19029989]

132. Dupasquier M, et al. The dermal microenvironment induces the expression of the alternative activation marker CD301/mMGL in mononuclear phagocytes, independent of IL-4/IL-13 signaling. J Leukoc Biol. 2006; 80:838-849. [PubMed: 16849611]

133. Taylor PR, et al. Dectin-2 is predominantly myeloid restricted and exhibits unique activationdependent expression on maturing inflammatory monocytes elicited in vivo. Eur J Immunol. 2005; 35:2163-2174. [PubMed: 15940672]

134. Hacker C, et al. Transcriptional profiling identifies Id 2 function in dendritic cell development. Nat Immunol. 2003; 4:380-386. [PubMed: 12598895]

135. Fainaru O, et al. Runx3 regulates mouse TGF-beta-mediated dendritic cell function and its absence results in airway inflammation. EMBO J. 2004; 23:969-979. [PubMed: 14765120] 


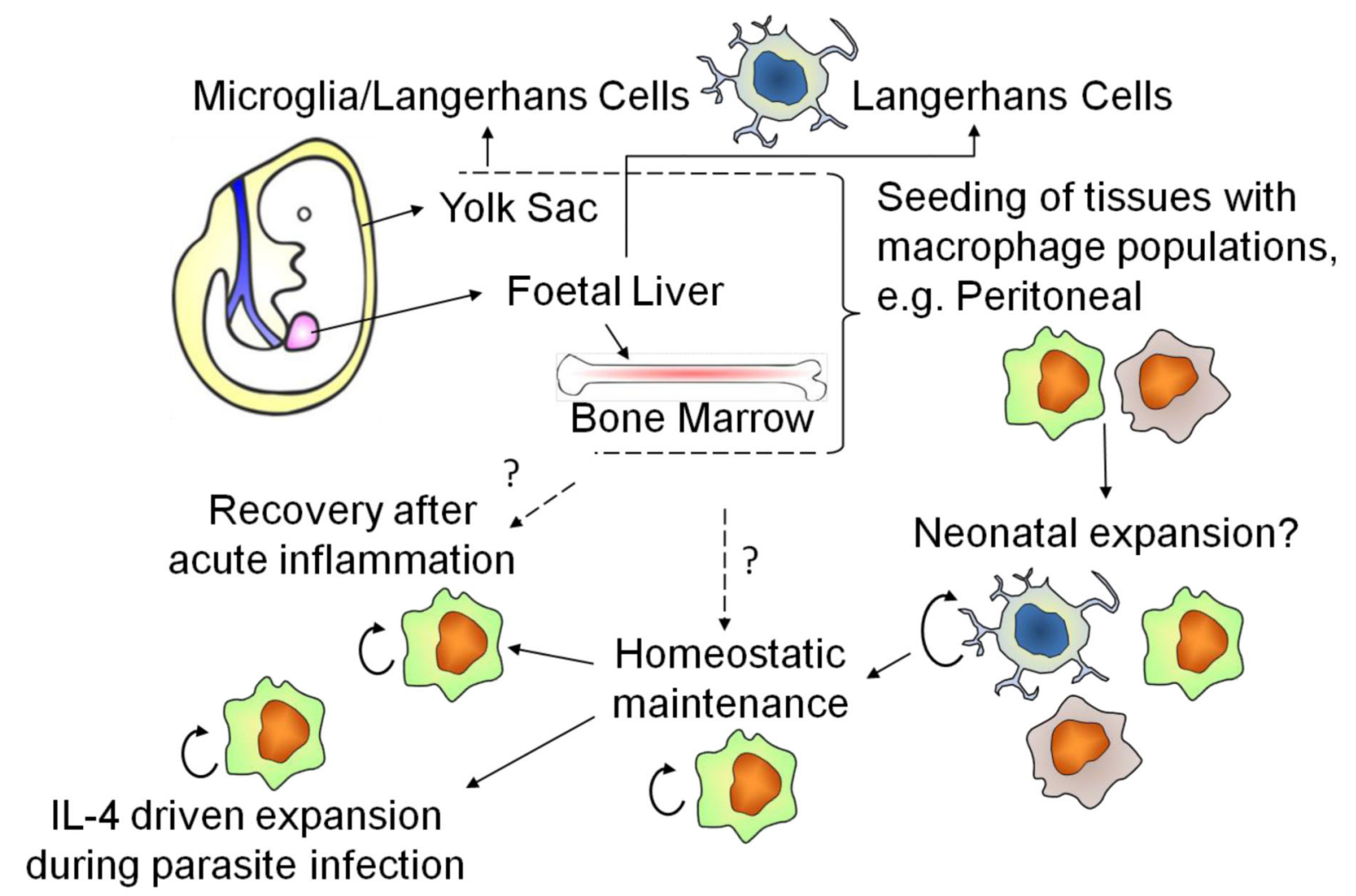

Figure 1. Origins and renewal of tissue-resident macrophages.

Recent fate mapping studies and single cell analyses in the mouse indicate that macrophages derived early in embryogenesis from the yolk sac can contribute to adult pools of tissue 'macrophages', such as Langerhans cells and microglia. Other tissues may be similarly seeded or established after definitive hematopoiesis in the fetal liver or bone marrow. Proliferative local-expansion of tissue macrophages in the neonatal period, followed by lowlevel self-renewal during adulthood appears sufficient to maintain many tissue resident populations. During the resolution of acute inflammation, local-proliferation can be enhanced to help restore homeostatic tissue resident macrophage populations. In the context of the $\mathrm{T}_{\mathrm{H}} 2$ environment associated with parasite infection, substantial IL-4-dependent proliferation can expand tissue resident macrophage numbers beyond that normally seen within the tissue. The exact contribution of bone marrow-derived inflammatory macrophages to these tissue resident pools is still unclear, but it appears likely to happen, although perhaps with tissue-specific variation. 


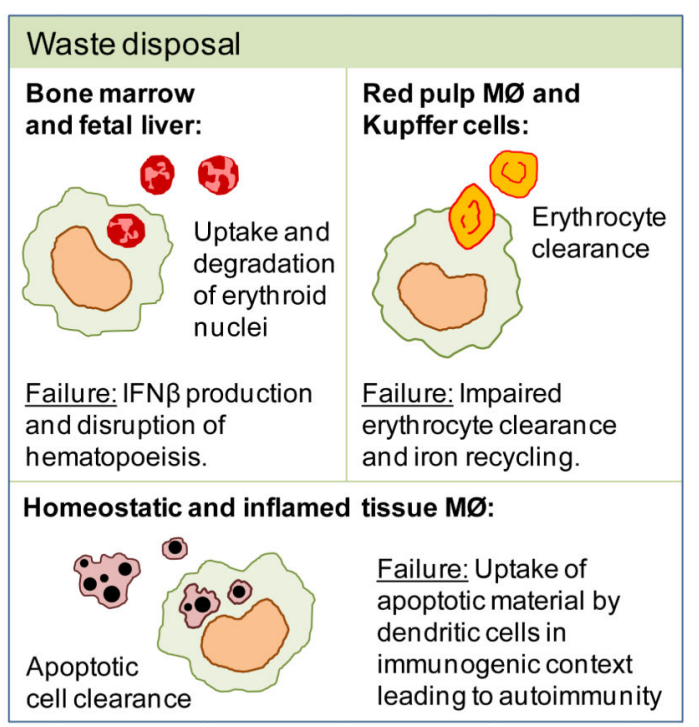

Initiation and resolution of inflammation

1. Pathogen recognition: e.g. TLRs and lectins.

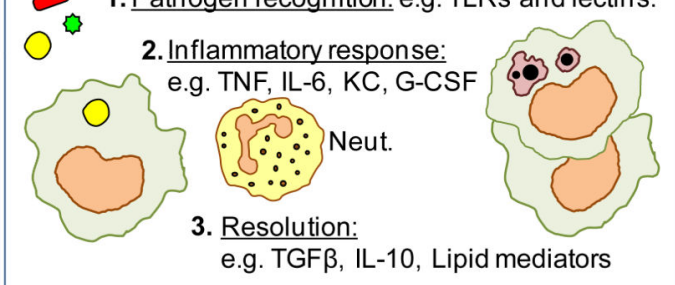

Failure: chronic inflammation, tissue damage, fibrosis.
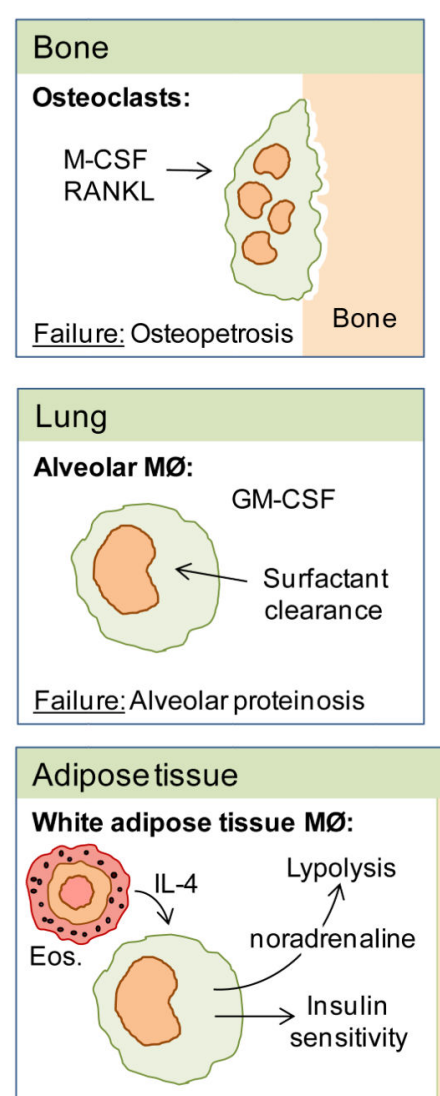

Failure: Insulin resistance

\section{Other development}

See Pollard, 2009 (Nat. Rev. Immunol. 9:259-270) for a

detailed discussion of the role

of macrophages in other

developmental processes.

This includes for example,

roles in:

- Ductal branching in mammary glands and pancreatic islets;

- Hypothalamic-pituitarygonadal development.

-Angiogenesis.

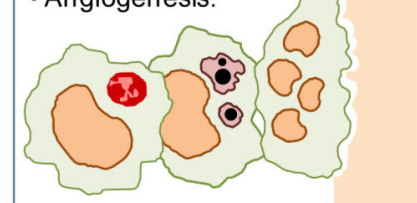

Brown adipose tissue Mø:

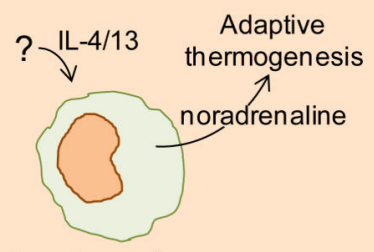

Failure: Loss of adaptive thermogenesis

Figure 2. Functions of tissue-resident macrophages.

Tissue-resident macrophages have broad roles in clearance (degradation of erythroid nuclei, senescent erythrocytes, apoptotic cells and pulmonary surfactant), development (bone degradation and angiogenesis) and the regulation of metabolism (regulation of insulin sensitivity and adaptive thermogenesis in adipose tissue). They also play a fundamental role as an immune sentinel, initiating inflammatory responses, clearing inflammatory debris and restoring homeostatic tissue environments. Neut, neutrophil; Eos, eosinophil. 


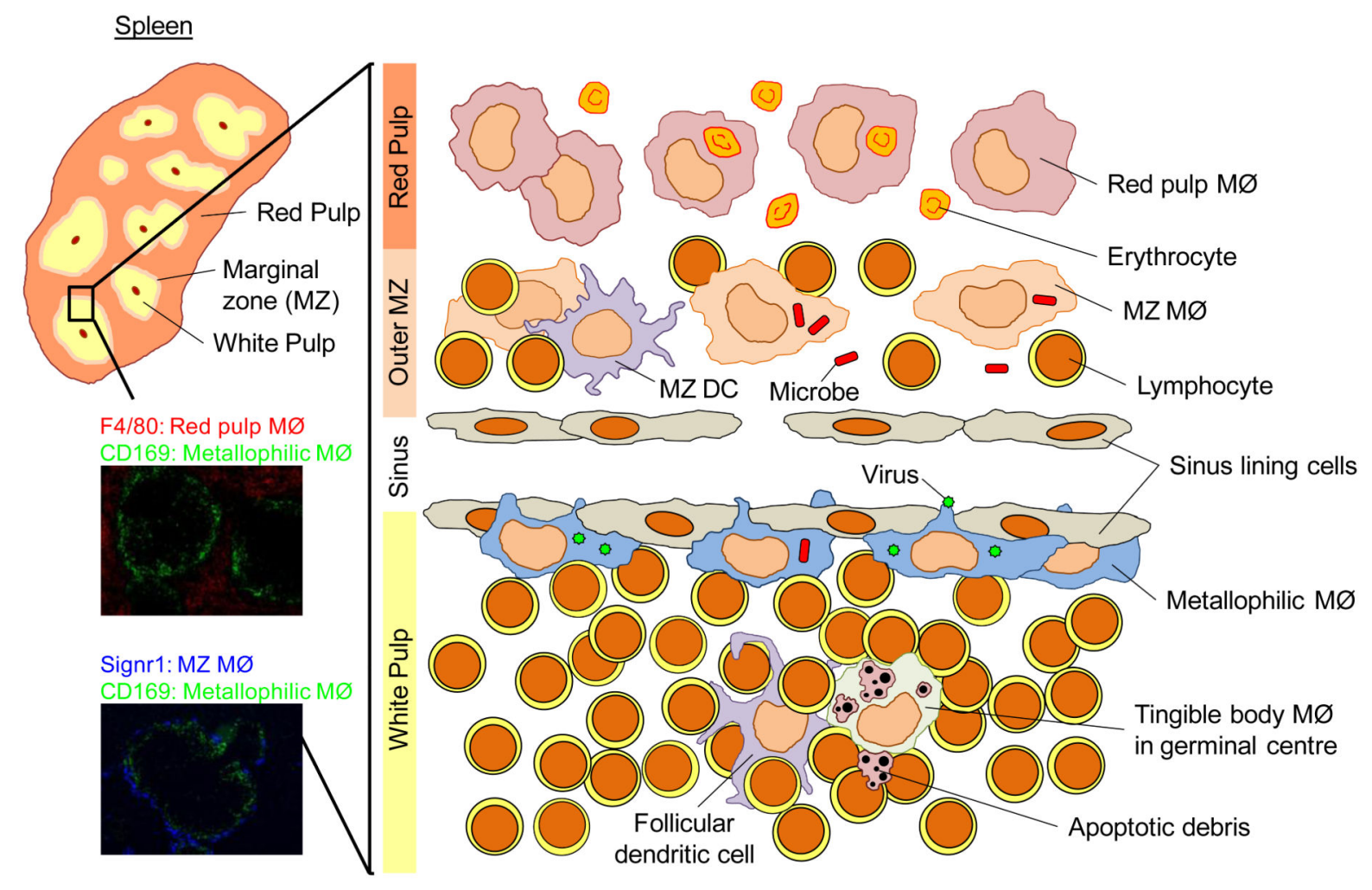

Figure 3. Microanatomy of the murine spleen showing discrete localization of splenic macrophage populations.

The murine spleen has discrete red and white pulp regions separated by a marginal zone $(\mathrm{MZ})$. The macrophages $(\mathrm{M} \varnothing)$ of the spleen are shown in their distinct anatomical locations. The red pulp macrophages (indicated immunohistochemically by F4/80 expression: red, top) are involved in iron processing. Marginal zone and metallophilic macrophages (indicated immunohistochemically by SIGNR1 (blue, bottom) and CD169 (green) expression respectively) play roles in the capture of microbes and viruses from the circulation. Tingible body macrophages in the B cell follicles clear the apoptotic cells that result from the germinal center reaction. Immunofluorescent images were kindly provided by $\mathrm{H}$. Veninga, E. Borg, G. Kraal, and J.M.M. den Haan. 


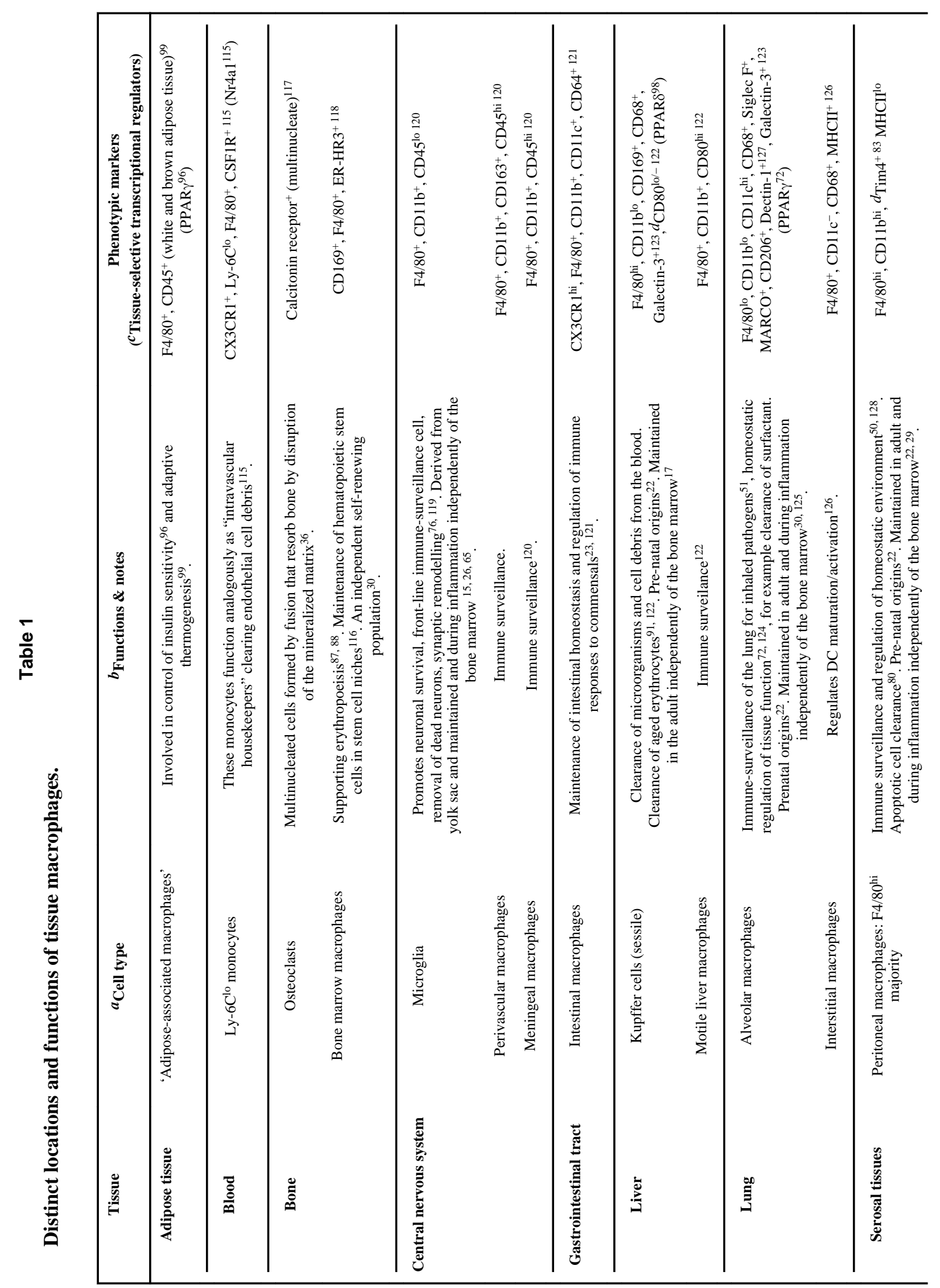

Nat Immunol. Author manuscript; available in PMC 2014 June 04. 


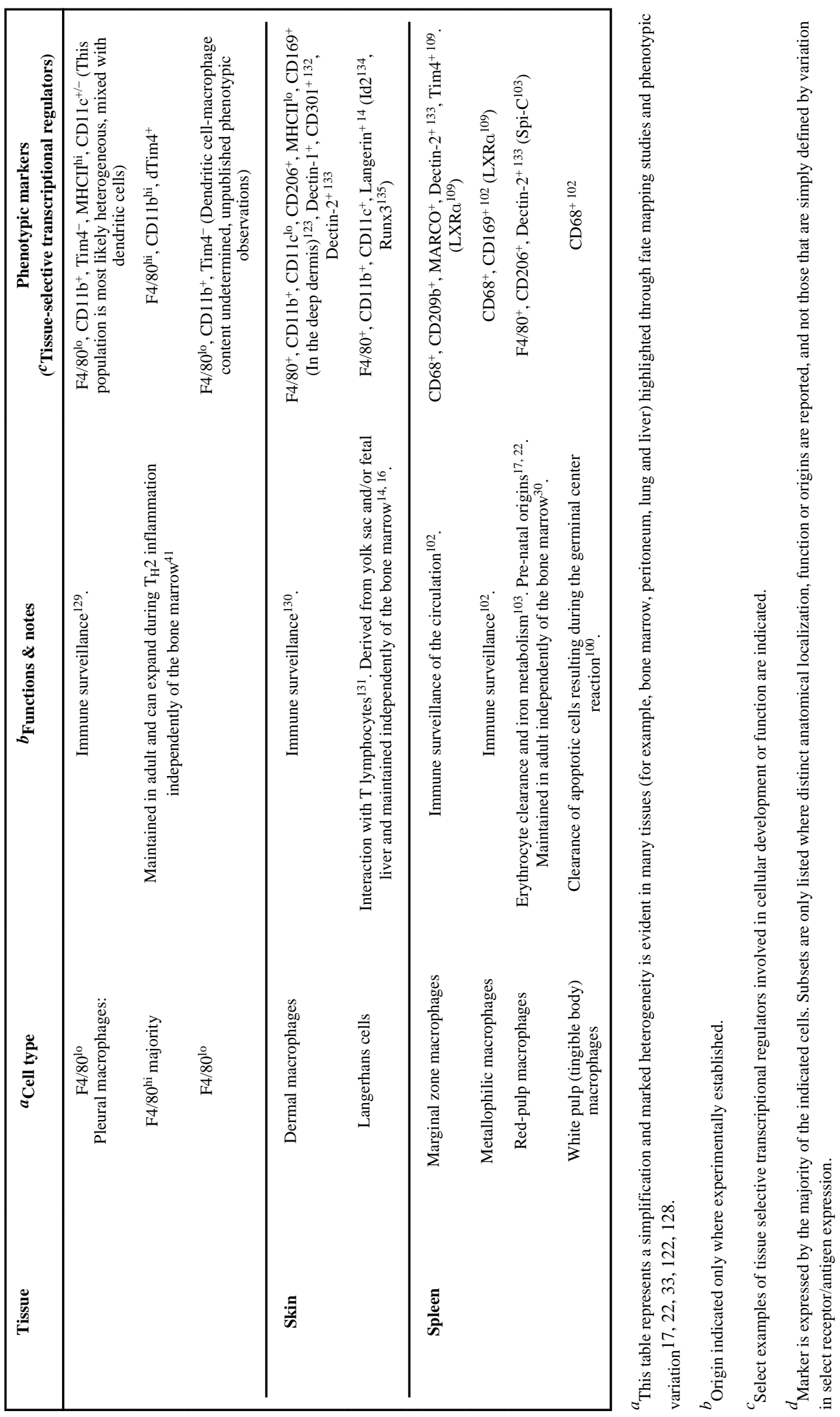

Nat Immunol. Author manuscript; available in PMC 2014 June 04. 